\title{
Analysis on the polymorphisms of site RS4977574, and RS1333045 in region 9p21 and the susceptibility of coronary heart disease in Chinese population
}

Lei Hua ${ }^{1 \dagger}$, Jin-Xia Yuan ${ }^{1 \dagger}$, Shu He${ }^{1}$, Chen-Hui Zhao', Qiao-Wei Jia', Jing Zhang ${ }^{1}$, Feng-Hui An², Zhao-Hong Chen², Li-Hua Li ${ }^{2}$, Lian-Sheng Wang ${ }^{1}$, Wen-Zhu Ma', Guang-Xu Xu ${ }^{3}$ and En-Zhi Jia ${ }^{1 *}$

\begin{abstract}
Background: Rs4977574 (A > G) and Rs1333045 (C > T) are both single nucleotide polymorphisms (SNPs) related with coronary artery disease, locating on chromosome 9p21.3. The study aimed to identify the correlation between rs4977574 and rs1333045 polymorphism genotypes and coronary heart disease (CHD) in a Chinese population.

Methods: Blood samples were collected from 855 subjects. A case-control study was used in this experiment, and 598 cases in the CHD group and 257 subjects in the control group were enrolled. Genotyping was identified by the Agena MassARRAY system. Statistical analysis was conducted by SPSS (Ver 16.0) and plink (Ver. 1.07, Shaun Purcell). Haplotype analysis was performed using Haploview software.

Results: Association analysis by plink indicated a significant difference in the allele distribution for single nucleotide polymorphisms between cases and controls (rs4977574 $P=0.003$, rs1333045 $P=0.035$ ). Fisher's exact test by plink proved that allele $\mathrm{G}$ may be associated with a higher risk of $\mathrm{CHD}(P=0.003$, odds ratio $(O R)=1.371)$ and the T allele was likely to reduce the risk of coronary events $(P=0.035, O R=0.798)$. The serum levels of apolipoprotein A (ApoA) were higher in subjects with the AG + AA genotype of rs 4977574 compared to those with the GG genotype $(P=$ 0.028). In the dominant model of rs 1333045 , the levels of ApoA were higher and LDL levels were lower in the TC+ $\Pi$ genotype than in the CC genotype.

Conclusions: The present study examined the association between the 9p21 chromosome rs4977574 and rs1333045 polymorphism genotypes and CHD in a population of Chinese patients. The G allele of rs4977574 and the $C$ allele of rs1333045 are the susceptibility sites of CHD.
\end{abstract}

Keywords: Coronary heart disease, SNP, Chromosome 9p21

\section{Background}

Coronary heart disease (CHD) is coronary atherosclerotic heart disease. CHD often occurs due to coronary atherosclerosis, and the rupture of the atherosclerotic plaque contributes to thrombosis, resulting in myocardial infarction, myocardial remodeling, heart failure, and even death. CHD is the top cause of human death in the

\footnotetext{
* Correspondence: enzhijia@njmu.edu.cn

†Lei Hua and Jin-Xia Yuan contributed equally to this work.

'Department of Cardiovascular Medicine, The First Affiliated Hospital of Nanjing Medical University, Guangzhou Road 300, Nanjing, Jiangsu Province 210029, China

Full list of author information is available at the end of the article
}

United States [1] and Asian countries such as China [2] and Japan [3]. CHD has been a hot topic in medical research because of its high incidence and high mortality. New research shows that CHD is a complex disease caused by a combination of genetic and environmental factors [4]. In addition to traditional risk factors such as age, smoking, high blood pressure and abnormal blood lipids, the combination of disease susceptibility genes and environmental factors affects the development of CHD. Identifying the susceptibility gene for coronary heart disease can help in early diagnosis and treatment. However, the exact mechanism of the disease is still

(c) The Author(s). 2020 Open Access This article is distributed under the terms of the Creative Commons Attribution 4.0 International License (http://creativecommons.org/licenses/by/4.0/), which permits unrestricted use, distribution, and reproduction in any medium, provided you give appropriate credit to the original author(s) and the source, provide a link to the Creative Commons license, and indicate if changes were made. The Creative Commons Public Domain Dedication waiver (http://creativecommons.org/publicdomain/zero/1.0/) applies to the data made available in this article, unless otherwise stated. 
unclear. In recent years, genetic predisposition has been thought to be closely associated with CHD and has been widely studied $[5,6]$.

Based on genome-wide association studies (GWAS), one of the important loci associated with CHD is the 9p21 locus, which has been introduced by the deCODE database. CDKN2B-AS1 of antisense noncoding RNA in the INK4 locus (ANIRL) is an antisense long noncoding RNA (lncRNA) mapped on the 9p21 locus [7] consisting of 19 exons, spanning $126.3 \mathrm{~kb}$ in the genome. The gene contributes to epigenetic inhibition of transcription by regulating Polycomb proteins [8]. According to the published literature, this gene is involved in developing cardiovascular diseases, diabetes, Alzheimer's disease, and several types of cancer [9-11]. Regulation of cardiac CDKN2BAS1 expression has been found to play a pivotal role in the development of CHD by altering the dynamics of vascular cell proliferation [12]. Rs4977574 is a nonprotein coding SNP $(A>G)$ that is located in proximity to the cyclindependent kinase inhibitor $2 \mathrm{~A}$ and $\mathrm{B}$ genes on chromosome 9p21.3. Rs4977574 has been recently found to be associated with the early onset of CHD, which is differentially expressed in a variety of tissues, such as vascular endothelial cells and smooth coronary muscle cells [13-16], and rs4977574 is characterized by a guanine nucleotide $(G)$ instead of an adenine nucleotide (A) [17]. $\operatorname{rs} 1333045(\mathrm{C}>\mathrm{T})$ is also an artery disease susceptibility SNP located in a conserved region in CDKN2B-AS1 that has been shown to have enhancer activity in a reporter gene experiment [13]. However, the underlying mechanisms in the regulation of rs4977574 and rs1333045 to CHD are unknown, and there is a lack of genetic evidence describing the pathogenesis in greater detail. Giving its limitations, coronary arteriography remains the gold standard for documenting the extent and severity of CHD.

Therefore, to provide a more detailed description of the correlation between Rs4977574 (A > G) and Rs1333045 $(\mathrm{C}>\mathrm{T})$ and $\mathrm{CHD}$ in a Chinese population, we conduct a case and control study by analysing the datasets collected from 855 subjects. It demonstrates that the $\mathrm{G}$ allele of rs4977574 and the $C$ allele of rs1333045 are the susceptibility sites of CHD, laying a foundation for further study about the mechanisms in the regulation of rs4977574 and rs1333045 to CHD.

\section{Methods}

\section{Study subjects}

All selected subjects signed informed consent, and the study was approved by the ethics committee of the First Affiliated Hospital of Nanjing Medical University and the Friendship Hospital of Ili Kazakh Autonomous Prefecture in China. There were 855 cases, including 629 males and 226 females, with an average age of 60 years. Patients with spastic angina pectoris, infections within the previous 2 weeks, heart failure, adrenal dysfunction, and thyroid dysfunction were excluded from the study.

In the CHD group, we selected a total of 598 patients (465 males and 133 females) aged 61 (53-70) years who were clinically diagnosed with CHD in the Friendship Hospital of Ili Kazakh Autonomous Prefecture in China from March 1, 2010 to April 31, 2015. The patients were confirmed by coronary angiography, which was performed by at least two experienced doctors simultaneously. In addition, 257 subjects (164 males and 93 females) aged 58 (49.5-66) years with negative angiography were selected as the control group. Coronary arteries were cannulated using either the Judkins technique [18] or a radial artery approach with $6 \mathrm{~F}$ catheters. $\mathrm{CHD}$ subjects were defined as at least one major epicardial vessel with $>50 \%$ stenosis; control subjects were defined as all of the major epicardial vessels with $<50 \%$ stenosis [19]. All subjects were unrelated Chinese to ensure the consistency of genetic background.

\section{Laboratory investigation}

In this study, four milliliters of peripheral blood was drawn from the subjects' veins after $12 \mathrm{~h}$ of fasting to perform biochemical assays on the second day of hospitalization. Each assay index was the reported clinical parameter associated with coronary heart disease [20-26]. Total cholesterol (TC, $\mathrm{mmol} / \mathrm{L}$ ), triglyceride (TG, $\mathrm{mmol} / \mathrm{L}$ ), creatinephosphokinase isoenzyme (CKMB, U/L), fasting high-density lipoprotein cholesterol (HDL-C, mmol/L), fasting low-density lipoprotein cholesterol (LDL-C, mmol/L), apolipoprotein A (ApoA, $\mathrm{g} / \mathrm{L})$, apolipoprotein $B(\mathrm{ApoB}, \mathrm{g} / \mathrm{L})$, glucose $(\mathrm{Glu}, \mathrm{mmol} / \mathrm{L})$, blood urea nitrogen (Bun, $\mathrm{mmol} / \mathrm{L}$ ) and serum creatinine $(\mathrm{Cre}, \mu \mathrm{mol} / \mathrm{L})$ were detected by the enzymatic method with an automated autoanalyzer (AU 2700 Olympus, 1st Chemical Ltd., Japan). Blood pressure was measured in the bare right arm with the participant seated, and the results were averaged over three measurements.

\section{Smoking and drinking}

For smoking, patients were classified as either nonsmokers (never smoking) or smokers (smoking now or in the past). Patients who smoked one cigarette a day were classified as current smokers. For drinking, patients were classified as nondrinkers (never having a drink) or drinkers (drinking now or in the past). Patients who drank at least $50 \mathrm{~g}$ of alcohol a week were considered drinkers.

\section{Hypertension}

Patients were defined as having hypertension if they had been previously diagnosed with hypertension and took antihypertensive drugs or if their systolic blood pressure was $140 \mathrm{mmHg}$ or their diastolic blood pressure was $90 \mathrm{mmHg}$. 


\section{Scoring of coronary angiogram}

Coronary angiography results were scored according to Gensini's scoring system. In Gensini's scoring system [27], the degree of coronary stenosis in the range of $0-25 \%$ was scored as 1 point, stenosis in the range of $25-50 \%$ was scored as 2 points, $50-75 \%$ was scored as 4 points, $75-90 \%$ was scored as 8 points, $90-99 \%$ was scored as 16 points, and completely occluded was scored as 32 points. Every stenosed segment was divided into 0.5 to 5 according to the importance of the segment's function. According to Gensini's standard, each major vessel and segment were graded, and the total score was calculated to show the severity of coronary lesion.

\section{DNA extraction and determination of SNP genotypes}

The experimental process of MassARRAY SNP typing is shown in Fig. 1. Gene polymorphisms were identified on the Agena MassARRAY system (Agena/Sequenom Inc., San Diego, CA, USA) according to the manufacturer's instructions. The literature and AssayDesigner3.1 software (Sequenom Inc., San Diego, CA, USA) were both used to design polymerase chain reaction (PCR) and single base extension primers. The primers were diluted for backup analysis by a professional biotech company.

The DNA in blood samples, tissues, cells and saliva was extracted using the finished product kit [Axygene Biotechnology (Hangzhou) Limited, Hangzhou City, China]. All DNA quality checks were qualified by using the NanoDrop2000 instrument (Thermo, Wilmington, DE, USA) for OD value detection and $1.25 \%$ agarose gel electrophoresis detection. All samples were transferred to a 96-well plate and stored for reserve at $-20^{\circ} \mathrm{C}$. DNA

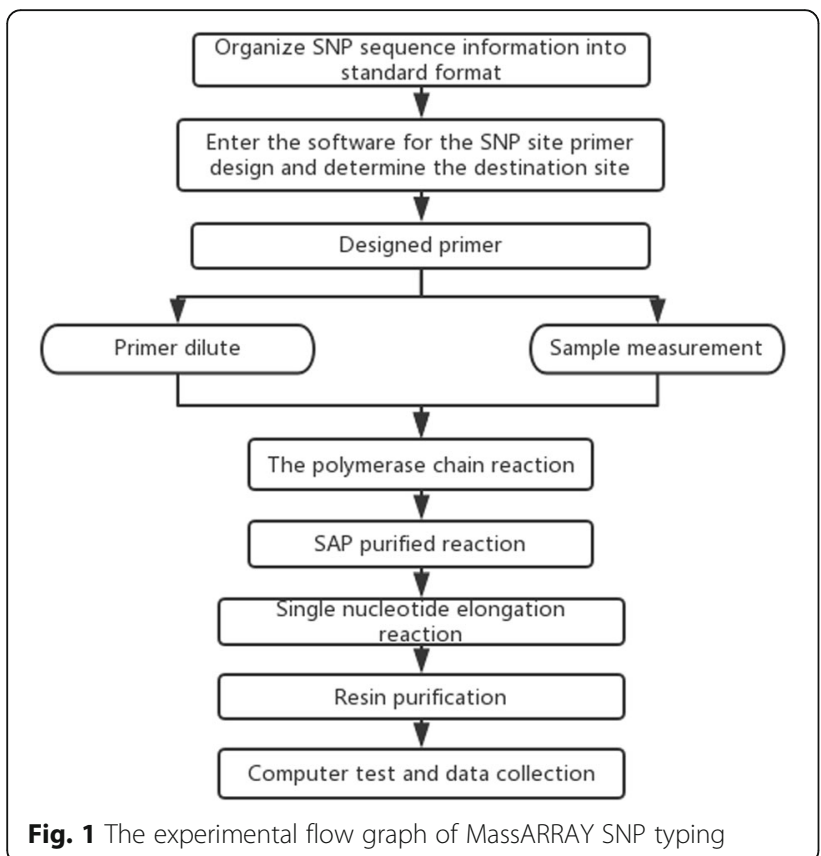

samples were amplified using standard PCR. The PCR master mix was configured in a $1.5 \mathrm{ml}$ EPtube and oscillated at low speed centrifugation. Eight or 12 channel shifters were chosen, and $4 \mu \mathrm{L}$ of PCR master mix were added to each well in 384 well plate, along with $1 \mu \mathrm{L}$ of template DNA $(20 \mathrm{ng} / \mu \mathrm{L})$. The 384-well plate was carefully sealed and pressed over each well to prevent evaporation during the PCR procedure. The plate was centrifuged at 1000 RPM for $1 \mathrm{~min}$. The reaction environment and procedures were set as $94{ }^{\circ} \mathrm{C}, 5 \mathrm{~min} ; 94{ }^{\circ} \mathrm{C}, 20 \mathrm{~s} ; 56{ }^{\circ} \mathrm{C}, 30 \mathrm{~s} ; 72^{\circ} \mathrm{C}, 1 \mathrm{~min} ; 72^{\circ} \mathrm{C}$, $3 \mathrm{~min}$. Forty-five amplification cycles were performed, and the reactants were stored at $4{ }^{\circ} \mathrm{C}$. The PCR products were treated with shrimp alkaline phosphatase (SAP) to remove the free dNTPs in the system. Five microliters of PCR products and $2 \mu \mathrm{L}$ of SAP mix were mixed in 384-well plates. The SAP reaction program was set to $37^{\circ} \mathrm{C}$ for $20 \mathrm{~min}$ and heated to $85^{\circ} \mathrm{C}$ for $5 \mathrm{~min}$ after centrifugation. The products were stored at $4{ }^{\circ} \mathrm{C}$. Two microliters of extend mix and $7 \mu \mathrm{L}$ of $\mathrm{PCR}+\mathrm{SAP}$ reaction reagent were mixed in each well of 384-well plates. The products were transferred into 384-well spectroCHIP bioarray by MassARRAY Nanodispenser RS1000 sampler (Agena, Inc.). The gene chip was analyzed by mass spectrometry (MALDI-TOF-MS). The original data and genotypes were obtained using MassARRAY TYPER 4.0 software (Agena, Inc).

\section{Statistical analysis}

All statistical analyses were performed with the Statistics Package for Social Sciences statistical software (Ver. 16.0, Chicago, USA) and plink (Ver. 1.07, Shaun Purcell). Quantitative variables are presented as the mean \pm standard deviation, while qualitative variables are expressed as percentages. Skewed data are presented as the median (interquartile range). Smoking status, drinking status, hypertension, gender and the SNP site were examined by the chi-square test. The serum level of ApoB was examined by independent samples $t$ test, and the remaining baseline characteristics were examined by the Mann-Whitney test for the demographics of the study population. To detect clinical parameters distributed in different genotypes, the serum level of ApoB was examined by one-way ANOVA, and the remaining baseline characteristics were examined by the Kruskal-Wallis test. Fisher's exact test was used for the distribution of alleles between the two groups. Logistic regression analysis was used to assess the significance of the association between SNP rs4977574, rs1333045 and CHD. Comparison of the genotype and environmental factors between cases and controls was determined by multivariable logistic regression analysis. The odds ratio $(O R)$ and $95 \%$ confidence intervals $(C I)$ were also calculated. The Hardy-Weinberg law tests the equilibrium of allele frequency and genotype frequency in two groups. Pairwise linkage disequilibrium $(L D)$ between sites was assessed by calculating D' and squared correlation $\left(r^{2}\right)$ using Haploview 
software. $P<0.05$ was considered statistically significant between the two groups.

The effects of the combination of gene and environment include not only the effects of both genes but also the superposition of gene and environmental effects and the multiplicative effect of gene and environmental effects. Through different models, we can distinguish the existence and size of interactions between two factors based on different models. Based on the additive model, there are several indicators for calculating interaction: (1) the interaction index (the synergy index $S, S$ ): when $S=1$, no interaction; when $S>1$, there is a positive interaction between the two factors; when $S<1$, there is a negative interaction between the two factors. (2) The attribution ratio of interaction (attributable proportion of interaction $A P$ ): it shows how much of the total effect is attributable to two-factor interactions. (3) The attribution ratio of pure interaction: $A P^{*}$ indicates the proportion of interaction between two factors, which is caused by two factors of gene and environment. (4) The interaction excess relative risk degree (relative excess risk of interaction, $R E R I$ ): this indicator indicates the difference between the combined effect of two factors and the sum of their individual effects and indicates the relationship between interaction and the effect of factors other than the two factors. If the unknown factor plays a great role, the interaction of the study becomes very minor and meaningless. Here, RERI is the two-factor interaction value based on the additive model.

\section{Results}

Hardy-Weinberg equilibrium

Hardy-Weinberg equilibrium (HWE) analysis revealed that the two study groups showed a remarkable genetic disequilibrium for both genotypes of rs4977574 and rs1333045 polymorphisms in this study, and the two groups were representative of the group.

\section{Characteristics of the subjects}

All 855 Chinese participants were genotyped for the rs4977574 and rs1333045 SNPs and included in the study. In this study, the CHD group included 465 males and 133 females, and the control group included 164 males and 93 females. The clinical characteristics of the participants are shown in Table 1 . There were significant differences in age $(P<0.001)$ and gender $(P<0.001)$ between the CHD and control groups; older or male subjects are presented in the CHD group. Smokers $(P=$ 0.031) are more susceptible to CHD, and the incidence of hypertension $(P=0.008)$ in the CHD group was significantly increased. The serum levels of CKMB $(P=$ $0.005)$ in the CHD group were higher than in the control group, while the levels of HDL $(P=0.015)$ were much lower. In addition, the content of Glu $(P<0.001)$ and Cre $(P=0.003)$ in CHDs was significantly higher than that in the controls. These variables are likely to be associated with CHD. The levels of TC and TG revealed no strong differences between CHDs and controls, which may be

Table 1 Demographics of the study population

\begin{tabular}{|c|c|c|c|c|}
\hline Variables & CHDs $(n=598)$ & Controls $(n=257)$ & Statistical parameter & $P$ value \\
\hline Age (years) & $61(53-70)$ & $58(49.5-66)$ & -3.839 & $<0.001$ \\
\hline Gender (male/ female) & $465 / 133$ & $164 / 93$ & 17.978 & $<0.001$ \\
\hline Smoking Status (yes/no) & $283 / 315$ & $101 / 156$ & 4.679 & 0.031 \\
\hline Drinking Status (yes/no) & $96 / 502$ & $34 / 223$ & 1.112 & 0.292 \\
\hline Hypertension (yes/no) & $324 / 274$ & $114 / 143$ & 6.941 & 0.008 \\
\hline CKMB (U/L) & $17(13-23)$ & $16(13-20)$ & -2.804 & 0.005 \\
\hline TC $(\mathrm{mmol} / \mathrm{L})$ & $4.65(3.88-5.52)$ & $4.60(3.91-5.38)$ & -0.837 & 0.403 \\
\hline TG $(\mathrm{mmol} / \mathrm{L})$ & $1.80(1.25-2.48)$ & $1.71(1.16-2.46)$ & -1.139 & 0.255 \\
\hline $\mathrm{HDL}(\mathrm{mmol} / \mathrm{L})$ & $1.33(1.10-1.62)$ & $1.41(1.18-1.68)$ & -2.426 & 0.015 \\
\hline $\mathrm{LDL}(\mathrm{mmol} / \mathrm{L})$ & $2.79(2.19-3.48)$ & $2.71(2.17-3.38)$ & -1.325 & 0.185 \\
\hline ApoA (g/L) & $1.29(1.14-1.45)$ & $1.30(1.18-1.49)$ & -1.747 & 0.081 \\
\hline ApoB (g/L) & $0.92 \pm 0.23$ & $0.90 \pm 0.21$ & -1.234 & 0.218 \\
\hline Glu (mmol/L) & $5.19(4.65-6.16)$ & $4.84(4.53-5.34)$ & -5.447 & $<0.001$ \\
\hline Bun (mmol/L) & $4.90(4.05-5.88)$ & $4.87(4.05-5.80)$ & -0.241 & 0.809 \\
\hline $\operatorname{Cre}(\mu \mathrm{mol} / \mathrm{L})$ & $72(62-81.25)$ & $69(60-78)$ & -2.937 & 0.003 \\
\hline RS4977574 (GG/AG/AA) & $152 / 297 / 149$ & $48 / 122 / 87$ & 8.686 & 0.012 \\
\hline RS1333045 (TT/TC/CC) & 138/292/168 & $73 / 127 / 57$ & 4.470 & 0.107 \\
\hline
\end{tabular}

Skewed data are presented as the median (interquartile range), normal data are presented as the mean \pm standard deviation, and categorical data are presented as the absolute value. Smoking status, drinking status, hypertension, gender and the SNP site were examined by the chi-square test. The serum level of ApoB was examined by the independent samples $t$ test, and the remaining baseline characteristics were examined by the Mann-Whitney test 
related to the use of lipid-lowering drugs in hospitalized patients.

\section{Clinical parameter distribution in different genotypes}

According to Table 1, the subjects were divided into three groups according to different genotypes: GG represents the homozygote of minor alleles, AG represents the heterozygote, and AA represents the homozygote of major alleles in rs4977574. TT represents the homozygote of minor alleles, TC represents the heterozygote, and CC represents the homozygote of major alleles in rs1333045. The three groups of genotypes were compared regarding clinical parameters, and the results are summarized in Table 2. Accordingly, no significant difference was observed between the frequencies of rs4977574 and rs1333045 in the distribution of age, gender, smoking

Table 2 Clinical parameters distributed in different genotypes

\begin{tabular}{|c|c|c|c|c|}
\hline RS4977574 & $\mathrm{GG}(n=200)$ & AG $(n=419)$ & AA $(n=236)$ & $P$ value \\
\hline Age (years) & $60(51-68)$ & $60(52-69)$ & $61(52.25-68)$ & 0.604 \\
\hline Gender (male/ female) & $143 / 57$ & $311 / 108$ & $175 / 61$ & 0.750 \\
\hline Smoking (yes/no) & $89 / 111$ & $189 / 230$ & $106 / 130$ & 0.990 \\
\hline Drinking (yes/no) & $26 / 174$ & $66 / 353$ & $38 / 198$ & 0.607 \\
\hline Hypertension (yes/no) & $99 / 101$ & $218 / 201$ & $121 / 115$ & 0.841 \\
\hline CKMB (U/L) & $17(13-22)$ & $17(13.40-21)$ & $16(12.10-21)$ & 0.145 \\
\hline TC $(\mathrm{mmol} / \mathrm{L})$ & $4.61(3.93-5.48)$ & $4.63(3.92-5.40)$ & $4.64(3.75-5.61)$ & 0.883 \\
\hline TG (mmol/L) & $1.85(1.26-2.41)$ & $1.82(1.23-2.55)$ & $1.68(1.13-2.43)$ & 0.188 \\
\hline $\mathrm{HDL}(\mathrm{mmol} / \mathrm{L})$ & $1.32(1.10-1.62)$ & $1.37(1.14-1.63)$ & $1.41(1.15-1.67)$ & 0.208 \\
\hline LDL (mmol/L) & $2.83(2.26-3.45)$ & $2.77(2.15-3.40)$ & $2.71(2.14-3.53)$ & 0.394 \\
\hline ApoA (g/L) & $1.27(1.13-1.42)$ & $1.30(1.16-1.46)$ & $1.30(1.16-1.46)$ & 0.086 \\
\hline ApoB (g/L) & $0.90 \pm 0.21$ & $0.93 \pm 0.22$ & $0.91 \pm 0.24$ & 0.305 \\
\hline Glu (mmol/L) & $5.04(4.55-5.80)$ & $5.07(4.63-6.00)$ & $5.09(4.59-6.07)$ & 0.504 \\
\hline Bun (mmol/L) & $4.87(4.02-5.61)$ & $4.87(4.06-6.08)$ & $4.94(3.96-5.80)$ & 0.381 \\
\hline $\operatorname{Cre}(\mu \mathrm{mol} / \mathrm{L})$ & $69(61-81)$ & $72(62-82)$ & $70(62-79.75)$ & 0.182 \\
\hline Gensini & $20(5-45.75)$ & $18(3-48)$ & $10(1.25-40)$ & 0.017 \\
\hline HWE & & & & 0.596 \\
\hline RS1333045 & $\Pi(n=211)$ & $\mathrm{TC}(n=419)$ & CC $(n=225)$ & $P$ value \\
\hline Age (years) & $61(53-68)$ & $60(52-70)$ & $60(51.5-68)$ & 0.697 \\
\hline Gender (male/ female) & $159 / 52$ & $304 / 115$ & $166 / 59$ & 0.751 \\
\hline Smoking (yes/no) & $97 / 114$ & $185 / 234$ & $102 / 123$ & 0.901 \\
\hline Drinking (yes/no) & $38 / 173$ & $63 / 356$ & 29/196 & 0.327 \\
\hline Hypertension (yes/no) & $106 / 105$ & $218 / 201$ & $114 / 111$ & 0.896 \\
\hline CKMB (U/L) & $16(12.4-21)$ & $17(13-21)$ & $17(13-22)$ & 0.446 \\
\hline TC $(\mathrm{mmol} / \mathrm{L})$ & $4.60(3.74-5.62)$ & $4.65(3.93-5.40)$ & $4.62(3.91-5.51)$ & 0.933 \\
\hline $\mathrm{TG}(\mathrm{mmol} / \mathrm{L})$ & $1.71(1.15-2.46)$ & $1.74(1.19-2.48)$ & $1.90(1.27-2.47)$ & 0.168 \\
\hline $\mathrm{HDL}(\mathrm{mmol} / \mathrm{L})$ & $1.38(1.13-1.67)$ & $1.38(1.14-1.63)$ & $1.32(1.11-1.62)$ & 0.336 \\
\hline $\mathrm{LDL}(\mathrm{mmol} / \mathrm{L})$ & $2.64(2.09-3.48)$ & $2.75(2.18-3.36)$ & $2.94(2.27-3.51)$ & 0.087 \\
\hline ApoA (g/L) & $1.29(1.15-1.46)$ & $1.30(1.17-1.49)$ & $1.27(1.13-1.43)$ & 0.129 \\
\hline ApoB (g/L) & $0.91 \pm 0.25$ & $0.93 \pm 0.22$ & $0.90 \pm 0.21$ & 0.382 \\
\hline Glu (mmol/L) & $5.10(4.59-6.04)$ & $5.05(4.63-6.02)$ & $5.07(4.57-5.79)$ & 0.493 \\
\hline Bun (mmol/L) & $4.85(3.91-5.74)$ & $4.88(4.07-6.14)$ & $4.93(4.04-5.78)$ & 0.392 \\
\hline $\operatorname{Cre}(\mu \mathrm{mol} / \mathrm{L})$ & $71(62.8-80)$ & $62(71-82)$ & $69(61-81)$ & 0.463 \\
\hline Gensini & $12(2-40)$ & $16(3-45)$ & $20(4-48)$ & 0.088 \\
\hline HWE & & & & 0.566 \\
\hline
\end{tabular}

HWE: $P$ value for Hardy-Weinberg equilibrium test. Skewed data are presented as the median (interquartile range), normal data are presented as the mean \pm standard deviation, and categorical data are presented as the absolute value. The serum level of ApoB was examined by one-way ANOVA, and the remaining baseline characteristics were examined by Kruskal-Wallis tests 
status, drinking status, hypertension, CKMB, TC, TG, HDL, LDL, ApoA, ApoB, Glu, Bun and Cre $(P>0.05)$. However, the Gensini score did differ significantly among the rs4977574 genotypes $(P=0.017)$. This indicates that the $\mathrm{G}$ allele was associated with the severity of $\mathrm{CHD}$. The allele frequency in subjects is all consistent with HWE $(P=0.596$ for rs4977574, $P=0.566$ for rs1333045).

\section{Serological biomarkers in the dominant model and recessive model}

Table 3 shows the serological biomarkers in the dominant model (rs4977574, AA vs. AG + GG; rs1333045, CC vs. TC $+\mathrm{TT}$ ) and recessive model (rs4977574, GG vs. $\mathrm{AA}+\mathrm{AG}$; rs1333045, TT vs. $\mathrm{TC}+\mathrm{CC}$ ). Table 3 shows that the serum levels of ApoA in the GG genotype were significantly lower than those in the AA+AG genotype $(P=0.028)$. In the dominant model of rs1333045, the serum levels of LDL in the CC genotype were higher than those in the TC + TT genotype $(P=0.032)$. In contrast, the serum levels of ApoA in the CC genotype were significantly lower than those in the $\mathrm{TC}+\mathrm{TT}$ genotype $(P=0.049)$. In addition, there were no differences between the two groups in other indicators. Moreover, significant difference of the serological biomarkers was observed neither in overdominant models of RS4977574 or RS1333045 (details seen in Additional file 2: Table S2).

\section{The analysis of the rs4977574 and rs1333045 gene polymorphism with CHD}

Fisher's exact test by plink proved that allele $G$ may be associated with a higher risk of CHD $(P=0.003, O R=$ $1.371,95 \% C I=1.113-1.689)$ and allele $\mathrm{T}$ was likely to reduce the incidence of coronary events $(P=0.035, O R=$ $0.798,95 \% C I=0.649-0.982$ ) (Table 4 ). The chi-square test showed consistent results, allele $\mathrm{G}$ of rs4977574 $(P=0.003, O R=1.371,95 \% C I=1.113-1.689)$ and allele $\mathrm{T}$ of $\mathrm{rs} 1333045(P=0.033, \mathrm{OR}=0.798,95 \% C I=0.649-$ 0.982) (Table 5).

The genotypic distribution and allele frequencies of rs4977574 and rs1333045 in CHDs and controls are shown in Table 6. The rs4977574-A allele frequencies were 0.498 in CHDs and 0.576 in controls, and rs4977574-G allele frequencies were 0.502 in CHDs and 0.424 in controls. The rs1333049-C allele frequency was 0.525 in the CHD group and 0.469 in the control group, and rs1333045- $\mathrm{T}$ allele frequencies were 0.475 in CHDs and 0.531 in controls.

The association between the genotypes of SNP rs4977574 and $\mathrm{CHD}$ risk was investigated by logistic regression analysis. For rs4977574, the CHD group included 149 individuals with the AA allele, 297 individuals with the AG allele, and 152 individuals with the GG allele. In the control group, 87, 122, and 48 subjects had AA, AG, and GG alleles, respectively. The study results revealed a significant difference between the CHDs and controls in the rs4977574 polymorphism $(P=0.012)$. The frequency of genotype GG $(P=0.042, O R=1.421,95 \% C I=1.014-1.993)$ and AG $(P=$ $0.004, O R=1.849,95 \% C I=1.217-2.810)$ were increased in the CHD group compared with the control group. In comparison to genotype $C C$, genotype TC significantly reduced the incidence of $\mathrm{CHD}(P=0.035, O R=0.641$ and $95 \% C I=$ 0.424-0.970). As reported in Table 6, the subjects with $\mathrm{AG}+\mathrm{GG} \quad(P=0.008, \quad O R=1.542, \quad 95 \% \quad C I=1.122-2.119)$ genotypes had a higher risk of CHD than those with AA genotype. Corresponding to this, in a recessive model (GG vs. (AA+AG)), rs4977574 may decrease the incidence of CHD $(P=0.033, O R=0.674$ and 95\% $C I=0.468-0.970)$. Moreover, rs1333045 was more likely to be a protective variant of CHD under the dominant model (CC vs. TC + TT, $P=0.048, A O R=0.700,95 \% C I=0.492-0.997)$ when the $P$ value was adjusted for age and gender. The gene polymorphisms of two sites in the CHD group and control group were in Hardy-Weinberg equilibrium.

\section{The relationship between the clinical characteristics and CHD}

For further study, we used the receiver operating characteristic (ROC) to describe the clinical indicators associated with $\mathrm{CHD}$. The five indicators of significance are age, CKMB, HDL, Glu and Cre. The area under curve (AUC) is 0.583 for age $(P<0.001,95 \% C I=0.541-0.624)$; 0.560 for CKMB $(P=0.005,95 \% \quad C I=0.520-0.601)$; 0.552 for HDL $(P=0.015,95 \% C I=0.511-0.593), 0.617$ for Glu $(P<0.001,95 \% C I=0.578-0.657)$; and 0.563 for Cre $(P=0.003,95 \% C I=0.521-0.605)$ (as shown in Table 7).

\section{The CHD prevalence and gene-environment interactions on the risk of $\mathrm{CHD}$}

In the logistic regression of interactions between $\mathrm{CHD}$, genotypes and variables, crossover analysis was used to reveal the relationship between $\mathrm{CHD}$ prevalence and gene-environment interactions on the risk of CHD (details seen in Additional file 1: Table S1).

In the dominant model of rs4977574, the AG + GG genotype showed an increased prevalence of CHD in participants who were $\geq 59.5$ years of age $(P<0.001$, $O R=2.304,95 \% C I=1.448-3.666)$ compared to the reference group who had AA genotype who were $<59.5$. Females had a lower risk of CHD than males (AA, $P=$ $0.004, O R=0.415,95 \% C I=0.229-0.753)$. In addition, the AA genotype without smoking or drinking of the reference group, the AA genotype with smoking $(P=$ 0.029, $O R=1.831,95 \% C I=1.063-3.154)$, the $A G+G G$ genotype with smoking $(P<0.001, O R=2.249,95 \% C I=$ 1.448-3.493), drinking $(P=0.034, O R=1.803,95 \% C I=$ $1.044-3.113)$ or without smoking $(P=0.005, O R=1.824$, $95 \% C I=1.201-2.77)$, and without drinking $(P=0.004$, $O R=1.661,95 \% C I=1.178-2.341)$ were more likely to 
Table 3 Comparisons of serological biomarkers in the dominant model and recessive model

\begin{tabular}{|c|c|c|c|c|}
\hline Dominant model of RS4977574 & AA & $A G+G G$ & Statistical parameter & $P$ value \\
\hline CKMB (U/L) & $16(12.1-21)$ & $17(13-22)$ & -1.925 & 0.054 \\
\hline TC $(\mathrm{mmol} / \mathrm{L})$ & $4.64(3.75-5.61)$ & $4.62(3.92-5.43)$ & -0.267 & 0.789 \\
\hline $\mathrm{TG}(\mathrm{mmol} / \mathrm{L})$ & $1.68(1.13-2.43)$ & $1.82(1.25-2.49)$ & -1.761 & 0.078 \\
\hline $\mathrm{HDL}(\mathrm{mmol} / \mathrm{L})$ & $1.41(1.15-1.67)$ & $1.36(1.12-1.62)$ & -1.059 & 0.290 \\
\hline LDL (mmol/L) & $2.71(2.14-3.53)$ & $2.79(2.22-3.42)$ & -0.658 & 0.510 \\
\hline ApoA (g/L) & $1.30(1.16-1.46)$ & $1.29(1.14-1.46)$ & -1.038 & 0.299 \\
\hline ApoB (g/L) & $0.91 \pm 0.24$ & $0.92 \pm 0.22$ & 0.547 & 0.585 \\
\hline Glu (mmol/L) & $5.09(4.59-6.07)$ & $5.07(4.62-5.90)$ & -0.075 & 0.940 \\
\hline Bun (mmol/L) & $4.94(3.96-5.80)$ & $4.87(4.06-5.88)$ & -0.150 & 0.881 \\
\hline Cre $(\mu \mathrm{mol} / \mathrm{L})$ & $70(62-79.75)$ & $71(62-82)$ & -0.547 & 0.584 \\
\hline Recessive model of RS4977574 & GG & $A A+A G$ & Statistical parameter & $P$ value \\
\hline CKMB (U/L) & $17(13-22)$ & $17(13-21)$ & -0.281 & 0.779 \\
\hline TC $(\mathrm{mmol} / \mathrm{L})$ & $4.61(3.93-5.48)$ & $4.63(3.88-5.48)$ & -0.306 & 0.760 \\
\hline $\mathrm{TG}(\mathrm{mmol} / \mathrm{L})$ & $1.85(1.26-2.41)$ & $1.75(1.20-2.50)$ & -1.060 & 0.289 \\
\hline $\mathrm{HDL}(\mathrm{mmol} / \mathrm{L})$ & $1.32(1.10-1.62)$ & $1.38(1.15-1.64)$ & -1.697 & 0.090 \\
\hline $\mathrm{LDL}(\mathrm{mmol} / \mathrm{L})$ & $2.83(2.26-3.45)$ & $2.74(2.15-3.43)$ & -1.348 & 0.187 \\
\hline ApoA (g/L) & $1.27(1.13-1.42)$ & $1.30(1.16-1.48)$ & -2.191 & 0.028 \\
\hline ApoB (g/L) & $0.90 \pm 0.21$ & $0.92 \pm 0.23$ & -1.168 & 0.243 \\
\hline Glu (mmol/L) & $5.04(4.55-5.80)$ & $5.07(4.62-6.03)$ & -1.072 & 0.284 \\
\hline Bun (mmol/L) & $4.87(4.02-5.61)$ & $4.89(4.06-5.94)$ & -1.349 & 0.177 \\
\hline Cre $(\mu \mathrm{mol} / \mathrm{L})$ & $69(61-81)$ & $71(62-81)$ & -1.469 & 0.142 \\
\hline Dominant model of RS1333045 & CC & $T C+\pi$ & Statistical parameter & $P$ value \\
\hline CKMB (U/L) & $17(13-22)$ & $16(13-21)$ & -0.628 & 0.530 \\
\hline TC $(\mathrm{mmol} / \mathrm{L})$ & $4.62(3.91-5.51)$ & $4.63(3.88-5.48)$ & -0.372 & 0.710 \\
\hline $\mathrm{TG}(\mathrm{mmol} / \mathrm{L})$ & $1.90(1.27-2.47)$ & $1.73(1.18-2.48)$ & -1.807 & 0.071 \\
\hline $\mathrm{HDL}(\mathrm{mmol} / \mathrm{L})$ & $1.32(1.11-1.62)$ & $1.38(1.14-1.64)$ & -1.469 & 0.142 \\
\hline $\mathrm{LDL}(\mathrm{mmol} / \mathrm{L})$ & $2.94(2.27-3.51)$ & $2.73(2.14-3.40)$ & -2.147 & 0.032 \\
\hline ApoA (g/L) & $1.27(1.13-1.43)$ & $1.30(1.16-1.48)$ & -1.970 & 0.049 \\
\hline ApoB (g/L) & $0.90 \pm 0.21$ & $0.92 \pm 0.23$ & -0.989 & 0.323 \\
\hline Glu (mmol/L) & $5.07(4.57-5.79)$ & $5.07(4.62-6.03)$ & -0.915 & 0.360 \\
\hline Bun (mmol/L) & $4.93(4.04-5.78)$ & $4.87(4.06-5.90)$ & -0.612 & 0.541 \\
\hline $\operatorname{Cre}(\mu \mathrm{mol} / \mathrm{L})$ & $69(61-81)$ & $71(62-81)$ & -1.175 & 0.240 \\
\hline Recessive model of RS1333045 & $\pi$ & $\mathrm{TC}+\mathrm{CC}$ & Statistical parameter & $P$ value \\
\hline CKMB (U/L) & $16(12.4-21)$ & $17(13-21.48)$ & -1.252 & 0.210 \\
\hline TC (mmol/L) & $4.60(3.74-5.62)$ & $4.65(3.92-5.44)$ & -0.159 & 0.873 \\
\hline $\mathrm{TG}(\mathrm{mmol} / \mathrm{L})$ & $1.71(1.15-2.46)$ & $1.81(1.24-2.48)$ & -1.131 & 0.258 \\
\hline $\mathrm{HDL}(\mathrm{mmol} / \mathrm{L})$ & $1.38(1.13-1.67)$ & $1.36(1.12-1.62)$ & -0.641 & 0.521 \\
\hline $\mathrm{LDL}(\mathrm{mmol} / \mathrm{L})$ & $2.64(2.09-3.48)$ & $2.79(2.22-3.43)$ & -1.220 & 0.223 \\
\hline ApoA (g/L) & $1.29(1.15-1.46)$ & $1.29(1.14-1.46)$ & -0.233 & 0.816 \\
\hline ApoB (g/L) & $0.91 \pm 0.25$ & $0.92 \pm 0.22$ & -0.576 & 0.565 \\
\hline Glu (mmol/L) & $5.10(4.59-6.04)$ & $5.05(4.62-5.92)$ & -0.401 & 0.688 \\
\hline Bun (mmol/L) & $4.85(3.91-5.74)$ & $4.90(4.06-5.89)$ & -0.941 & 0.347 \\
\hline Cre $(\mu \mathrm{mol} / \mathrm{L})$ & $71(62.8-80)$ & $71(61.05-81)$ & -0.026 & 0.979 \\
\hline
\end{tabular}


Table 4 Fisher's exact test of alleles

\begin{tabular}{llllll}
\hline & A1 & A2 & $O R(95 \%$ Cl & $S E$ & $P$ \\
\hline Rs4977574 & $G$ & A(reference) & $1.371(1.113-1.689)$ & 0.1063 & 0.003 \\
Rs1333045 & $\mathrm{T}$ & C(reference) & $0.798(0.649-0.982)$ & 0.1057 & 0.035 \\
\hline
\end{tabular}

OR Odds ratio, 95\% Cl 95\% confidence interval, SE Standard error

have CHD. Patients who do not have hypertension (AG + GG, $P=0.004, O R=1.914,95 \% C I=1.230-2.977)$, and who have hypertension (AA, $P=0.010, O R=2.028$, 95\% $C I=1.184-3.473 ;$ AG + GG, $P<0.001, O R=2.487$, 95\% $C I=1.591-3.887$ ) have an increase in CHD prevalence. For the subjects had $\mathrm{CKMB}<25.9$ (AG + GG, $P=$ 0.016, $O R=1.515,95 \% C I=1.080-2.123), C K M B \geq 25.9$ (AA, $P=0.012$, OR $=3.262,95 \% C I=1.296-8.212$; AG + GG, $\quad P<0.001, \quad O R=6.075, \quad 95 \% \quad C I=2.982-12.375$ ) existed as a risk factor compared with the AA genotype where $\mathrm{CKMB}<25.9$. Similarly, the $\mathrm{AG}+\mathrm{GG}$ genotype with Glu $<5.445(P=0.004, O R=1.750,95 \% C I=1.194-$ 2.564) and the AA or AG + GG genotype with Glu $\geq$ 5.445 (AA, $P<0.001, O R=3.551,95 \% C I=1.910-6.603$; AG + GG, $P<0.001, O R=4.399,95 \% C I=2.721-7.113)$ may have a greater chance of having $\mathrm{CHD}$ compared to the reference group (Glu $<5.445$, AA). Moreover, the $\mathrm{AG}+\mathrm{GG}$ genotype increased the risk of CHD in subjects with $\mathrm{Cre} \geq 73.2(P<0.001, O R=2.453,95 \% C I=1.565-$ 3.844).

In the recessive model of rs 4977574 , females had a lower risk of CHD (AG + AA, $P<0.001, O R=0.333,95 \%$ $C I=0.201-0.551$ ). No drinking also contributed to health (AG + AA, $P=0.019, O R=0.625,95 \% C I=0.422$ $0.925)$. The AG + AA genotype exists as a positive factor for health in subjects with $\mathrm{CKMB}<25.9$ (AG + AA, $P=$ $0.031, \quad O R=0.654,95 \% \quad C I=0.444-0.962), \quad$ Glu $<5.445$ (AG + AA, $P=0.003, O R=0.521,95 \% C I=0.338-0.802$ ), and HDL $>1.325$ (AG + AA, $P=0.001, O R=0.405,95 \%$ $C I=0.236-0.697 ;$ GG $, P=0.05, O R=0.516,95 \% C I=$ 0.267-1.000). However, $\mathrm{CKMB} \geq 25.9$ (AG $+\mathrm{AA}, \quad P=$ $0.005, \quad O R=2.675,95 \% \quad C I=1.336-5.356), \quad$ Glu $\geq 5.445$ (AG + AA, $P=0.034, O R=1.741,95 \% C I=1.041-2.911$ ) or Cre $\geq 73.2$ (GG, $P=0.038, O R=2.122,95 \% C I=$ 1.041-4.328) increased the prevalence of CHD.

For rs1333045, in the dominant model, female (CC, $P=0.037, \quad O R=0.501,95 \% C I=0.262-0.958 ; \mathrm{TC}+\mathrm{TT}$, $P<0.001, \quad O R=0.365, \quad 95 \% \quad C I=0.226-0.590)$ or no drinking $(\mathrm{TC}+\mathrm{TT}, \quad P=0.042, \quad O R=0.680, \quad 95 \% \quad C I=$ $0.469-0.985)$ possibly reduced the risk of CHD. There are other protective factors, $\mathrm{TC}+\mathrm{TT}$ genotype with
HDL $<1.325$ (CC, $P=0.023, O R=0.530,95 \% C I=0.307-$ 0.916), $\mathrm{HDL} \geq 1.325$ (CC, $P=0.005, \mathrm{OR}=0.405,95 \% \mathrm{CI}=$ $0.217-0.757 ; \mathrm{TC}+\mathrm{TT}, P=0.001, \quad O R=0.394,95 \% C I=$ $0.232-0.670$ ) or Glu $<5.445$ (TC+TT, $P=0.006, O R=$ $0.559,95 \% C I=0.371-0.843)$. In contrast, all other interactions increased the risk of CHD. Subjects with age $\geq 59.5$ (CC, $\quad P=0.006, \quad O R=2.400, \quad 95 \% \quad C I=1.292-4.459$ ), $C K M B \geq 25.9(C C, P=0.040, O R=3.118,95 \% C I=1.052-$ 9.243; TC+ TT, $P=0.003, \quad O R=2.825,95 \% \quad C I=1.429$ 5.588), Glu $\geq 5.445$ (TC+ TT, $P=0.009, O R=1.949,95 \%$ $C I=1.179-3.225)$ and $\mathrm{Cre} \geq 73.2(\mathrm{CC}, P=0.017, O R=$ 2.221, 95\% $C I=1.157-4.265$ ) may be associated with CHD.

In the recessive model of rs1333045, compared to the reference group, the likelihood of onset is reduced in females (TT, $P=0.003, O R=0.377,95 \% C I=0.198-0.717$ ). However, when other factors, such as age $\geq 59.5$ ( TC + CC, $P=0.003, O R=2.042,95 \% C I=1.268-3.291$ ), smoking (TT, $P=0.029, O R=1.916,95 \% C I=1.068-3.435$; $\mathrm{TC}+\mathrm{CC}, P=0.003, O R=1.983,95 \% C I=1.256-3.130)$, hypertension (TC $+\mathrm{CC}, P=0.002, O R=2.048,95 \% C I=$ 1.291-3.247), $\mathrm{CKMB} \geq 25.9$ (TT, $P=0.017, O R=3.102$, 95\% $C I=1.226-7.846 ; \mathrm{TC}+\mathrm{CC}, P<0.001, O R=5.521$, 95\% $C I=2.684-11.357$ ), Glu $\geq 5.445 \quad$ (TT, $P<0.001$, $O R=3.550,95 \% C I=1.785-7.061 ; \mathrm{TC}+\mathrm{CC}, P<0.001$, $O R=3.654,95 \% C I=2.263-5.900), C r e \geq 73.2$ (TT, $P=$ 0.047, $O R=1.812,95 \% C I=1.007-3.260 ; \mathrm{TC}+\mathrm{CC}, P<$ $0.001, O R=2.218,95 \% C I=1.399-3.517)$ exist, the risk of CHD increased.

The synergistic effect between dominant model, recessive model and classical risk factors

The analysis of the associations between gene and classical risk factors is shown in Table 8. We found a positive correlation between the dominant model of rs4977574 and age $\left(S=3.34, A P=0.40\right.$, and $\left.A P^{*}=0.70\right)$, and the proportion of CHD attributable to the interaction between the dominant model, and age was as high as $70 \%$. The same positive correlation was found between the dominant model and CKMB $\left(S=1.83, A P=0.38\right.$, and $\left.A P^{*}=0.45\right)$. There is a positive interaction between Glu $(S=1.03, A P=0.02$, and $\left.A P^{*}=0.03\right)$, Cre $\left(S=1.91, A P=0.28\right.$, and $\left.A P^{*}=0.48\right)$ and the dominant model of rs4977574. In the recessive model of rs4977574 and rs1333045, CKMB shows a positive interaction between them (rs4977574, $S=1.23, A P=0.12$, and $A P^{*}=0.19 ;$ rs1333045, $S=1.86, A P=0.38$, and $A P^{*}=0.46$ ). In contrast, a negative interaction was found between HDL and the recessive model of rs4977574 $(S=0.67, A P=0.73$,

Table $\mathbf{5}$ The chi-square test of alleles

\begin{tabular}{lllllll}
\hline & A1 & A2 & OR (95\% Cl) & CHISQ & SE & $P$ \\
\hline Rs4977574 & G & A(reference) & $1.371(1.113-1.689)$ & 8.851 & 0.1063 & 0.003 \\
Rs1333045 & $\mathrm{T}$ & C(reference) & $0.798(0.649-0.982)$ & 4.545 & 0.1057 & 0.033 \\
\hline
\end{tabular}

OR Odds ratio, 95\% Cl 95\% confidence interval, SE Standard error 
Table 6 Logistic analysis of the association between SNPs rs4977574 and rs1333045 and CHD risk

\begin{tabular}{|c|c|c|c|c|c|c|}
\hline Rs4977574 (A > G) & CHD $(n=598)$ & Control $(n=257)$ & $O R(95 \% C l)$ & $P$ value & $A O R^{*}(95 \% C l)$ & $P^{*}$ value \\
\hline AA & 149 & 87 & 1.000 (reference) & 0.012 & 1.000 (reference) & 0.005 \\
\hline AG & 297 & 122 & $1.849(1.217-2.810)$ & 0.004 & $2.035(1.323-3.132)$ & 0.001 \\
\hline GG & 152 & 48 & $1.421(1.014-1.993)$ & 0.042 & $1.452(1.026-2.054)$ & 0.035 \\
\hline Dominant model (AAvsAG+GG) & $149 / 449$ & $87 / 170$ & $1.542(1.122-2.119)$ & 0.008 & $1.612(1.163-2.235)$ & 0.004 \\
\hline Recessive model (GGvsAA+AG) & $152 / 446$ & $48 / 209$ & $0.674(0.468-0.970)$ & 0.033 & $0.620(0.427-0.902)$ & 0.012 \\
\hline Allele A frequency & $595(49.75 \%)$ & $296(57.59 \%)$ & $O R(95 \% C l)$ & $P$ value & $A O R^{*}(95 \% C l)$ & $P^{*}$ value \\
\hline Allele G frequency & $601(50.25 \%)$ & $218(42.41 \%)$ & & & & \\
\hline HWE & 0.871 & 0.651 & & & & \\
\hline RS1333045 (C > T) & $\mathrm{CHD}(\mathrm{n}=598)$ & Control $(n=257)$ & & & & \\
\hline CC & 168 & 57 & 1.000 (reference) & 0.108 & 1.000 (reference) & 0.060 \\
\hline TC & 292 & 127 & $0.641(0.424-0.970)$ & 0.035 & $0.599(0.392-0.915)$ & 0.018 \\
\hline$\Pi$ & 138 & 73 & $0.780(0.541-1.124)$ & 0.183 & $0.759(0.522-1.105)$ & 0.151 \\
\hline Dominant model (CCvsTC+TT) & $168 / 430$ & $57 / 200$ & $0.729(0.517-1.029)$ & 0.072 & $0.700(0.492-0.997)$ & 0.048 \\
\hline Recessive model (TTvsCC+TC) & $138 / 460$ & $73 / 184$ & $1.322(0.950-1.842)$ & 0.098 & $1.392(0.991-1.955)$ & 0.057 \\
\hline Allele $C$ frequency & $628(52.51 \%)$ & $241(46.89 \%)$ & & & & \\
\hline Allele T frequency & $568(47.49 \%)$ & $273(53.11 \%)$ & & & & \\
\hline HWE & 0.609 & 0.900 & & & & \\
\hline
\end{tabular}

In the SNP rs4977574, GG represents the homozygote of minor alleles, AG represents the heterozygote, and AA represents the homozygote of major alleles. In the SNP rs1333045, TT represents the homozygote of minor alleles, TC represents the heterozygote, and CC represents the homozygote of major alleles AOR Adjusted odds ratio

*Adjusted for age and gender

and $\left.A P^{*}=-0.50\right)$ and between HDL and the dominant model of $\operatorname{rs} 1333045\left(S=0.57, A P=1.16\right.$, and $\left.A P^{*}=-0.76\right)$.

\section{Haplotype analysis between rs4977574 and rs1333045}

The LD plot on the left indicates the linkage of the gene SNP. $R^{2}$ refers to the statistical correlation between the two sites. An LD plot was constructed based on the pairwise correlation between the two sites on the 9p21 locus, but unfortunately, it shows that there is no linkage disequilibrium between two sites $\left(D^{\prime}=0.92\right.$ and $\left.r^{2}=0.75\right)$ (Fig. 2).

\section{Discussion}

CHD is a major cause of morbidity and mortality worldwide and represents a tremendous social and economic burden on society [28]. Recent genome-wide association studies have indicated that there is an association between increased susceptibility to coronary artery disease and specific SNPs within the genome that play a role in conjunction with other known traditional CHD risk factors, but the exact mechanism is unclear. Clinical observation has found that atherosclerosis is one of the major pathophysiological mechanisms of CHD [29]. Endothelial cells

Table 7 Receiver operating characteristic curve analyses for predicting CHD prevalence

\begin{tabular}{|c|c|c|c|c|c|c|}
\hline Variables & AUC (95\% Cl) & $P$ value & Cut-off & Sensitivity & Specificity & Youden index \\
\hline Age (years) & $0.583(0.541-0.624)$ & $<0.001$ & 59.5 & 0.562 & 0.556 & 0.118 \\
\hline CKMB (U/L) & $0.560(0.520-0.601)$ & 0.005 & 25.9 & 0.199 & 0.938 & 0.137 \\
\hline TC $(\mathrm{mmol} / \mathrm{L})$ & $0.518(0.477-0.559)$ & 0.403 & - & - & - & - \\
\hline $\mathrm{TG}(\mathrm{mmol} / \mathrm{L})$ & $0.525(0.482-0.567)$ & 0.255 & - & - & - & - \\
\hline $\mathrm{HDL}(\mathrm{mmol} / \mathrm{L})$ & $0.552(0.511-0.593)$ & 0.015 & 1.325 & 0.503 & 0.385 & 0.111 \\
\hline LDL (mmol/L) & $0.529(0.487-0.570)$ & 0.185 & - & - & - & - \\
\hline ApoA (g/L) & $0.538(0.500-0.583)$ & 0.081 & - & - & - & - \\
\hline ApoB (g/L) & $0.523(0.482-0.564)$ & 0.280 & - & - & - & - \\
\hline Glu (mmol/L) & $0.617(0.578-0.657)$ & $<0.001$ & 5.445 & 0.418 & 0.794 & 0.212 \\
\hline Bun (mmol/L) & $0.505(0.463-0.547)$ & 0.809 & - & - & - & - \\
\hline $\operatorname{Cre}(\mu \mathrm{mol} / \mathrm{L})$ & $0.563(0.521-0.605)$ & 0.003 & 73.2 & 0.463 & 0.654 & 0.117 \\
\hline
\end{tabular}


Table 8 The indexes of the synergistic effect between the dominant model, recessive model and risk factors

\begin{tabular}{|c|c|c|c|c|}
\hline & S & $A P$ & $A P^{a}$ & RERI \\
\hline \multicolumn{5}{|c|}{ Variables- Dominant model of rs 4977574} \\
\hline Age- $A A / A G+G G$ & 3.34 & 0.40 & 0.70 & 0.913 \\
\hline Gender- AA/AG + GG & 1.63 & -0.11 & 0.39 & -0.085 \\
\hline Smoke- AA/AG + GG & 0.75 & -0.18 & -0.33 & -0.406 \\
\hline Drink- $A A / A G+G G$ & 0.56 & -0.35 & -0.80 & -0.639 \\
\hline Hypertension- AA/AG + GG & 0.77 & -0.18 & -0.31 & -0.455 \\
\hline$C K M B-A A / A G+G G$ & 1.83 & 0.38 & 0.45 & 2.298 \\
\hline $\mathrm{HDL}-\mathrm{AA} / \mathrm{AG}+\mathrm{GG}$ & 0.02 & -0.30 & -48.24 & -0.305 \\
\hline Glu- AA/AG + GG & 1.03 & 0.02 & 0.03 & 0.098 \\
\hline Cre- $A A / A G+G G$ & 1.91 & 0.28 & 0.48 & 0.691 \\
\hline \multicolumn{5}{|c|}{ Variables- Recessive model of rs 4977574} \\
\hline Age- $G G / A G+A A$ & 0.25 & -0.25 & -2.96 & -0.273 \\
\hline Gender- GG/AG + AA & 0.92 & -0.18 & -0.09 & 0.060 \\
\hline Smoke- GG/AG + AA & 0.00 & -0.62 & -830.35 & -0.618 \\
\hline Drink- GG/AG + AA & 0.22 & 0.47 & -3.45 & 0.417 \\
\hline Hypertension- GG/AG + AA & -0.00 & -0.19 & 637.34 & -0.186 \\
\hline CKMB- GG/AG + AA & 1.23 & 0.12 & 0.19 & 0.316 \\
\hline $\mathrm{HDL}-\mathrm{GG} / \mathrm{AG}+\mathrm{AA}$ & 0.67 & 0.73 & -0.50 & 0.297 \\
\hline Glu- GG/AG + AA & -19.62 & 0.45 & 1.05 & 0.779 \\
\hline Cre- $G G / A G+A A$ & 0.16 & -0.63 & -5.19 & -0.715 \\
\hline \multicolumn{5}{|c|}{ Variables- Dominant model of rs 1333045} \\
\hline Age- $C C / T C+\pi$ & 0.24 & -0.76 & -3.18 & -1.007 \\
\hline Gender- CC/TC + TT & 0.82 & 0.38 & -0.22 & 0.140 \\
\hline Smoke- $\mathrm{CC} / \mathrm{TC}+\mathrm{T}$ & 0.11 & -0.49 & -7.75 & -0.524 \\
\hline Drink- $\mathrm{CC} / \mathrm{TC}+\pi$ & 0.09 & 0.42 & -10.57 & 0.406 \\
\hline Hypertension- $\mathrm{CC} / \mathrm{TC}+\pi$ & 0.24 & -0.37 & -3.17 & -0.414 \\
\hline $\mathrm{CKMB}-\mathrm{CC} / \mathrm{TC}+\mathrm{TT}$ & 1.00 & -0.00 & -0.00 & -0.003 \\
\hline $\mathrm{HDL}-\mathrm{CC} / \mathrm{TC}+\pi$ & 0.57 & 1.16 & -0.76 & 0.459 \\
\hline Glu- CC/TC+TT & -54.49 & 0.50 & 1.02 & 0.967 \\
\hline Cre- $\mathrm{CC} / \mathrm{TC}+\pi$ & 0.23 & -0.65 & -3.34 & -0.808 \\
\hline \multicolumn{5}{|c|}{ Variables- Recessive model of rs 1333045} \\
\hline Age- $T T / T C+C C$ & 1.85 & 0.23 & 0.46 & 0.479 \\
\hline Gender- TT/TC + CC & 0.82 & 0.11 & -0.22 & 0.075 \\
\hline Smoke- TT/TC + CC & 0.65 & -0.27 & -0.54 & -0.529 \\
\hline Drink- TT/TC+CC & 0.30 & -0.81 & -2.33 & -1.230 \\
\hline Hypertension- TT/TC + CC & 0.85 & -0.09 & -0.17 & -0.180 \\
\hline CKMB- TT/TC + CC & 1.86 & 0.38 & 0.46 & 2.097 \\
\hline $\mathrm{HDL}-\mathrm{TT} / \mathrm{TC}+\mathrm{CC}$ & -2.37 & -0.23 & 1.42 & -0.199 \\
\hline Glu- TT/TC + CC & 0.89 & -0.09 & -0.13 & -0.339 \\
\hline Cre- TT/TC + CC & 1.00 & -0.00 & -0.00 & -0.002 \\
\hline
\end{tabular}

$S$ The synergy index $\mathrm{S}, A P$ Attributable proportion of interaction, $A P^{a}$ Attributable proportion of pure interaction, $R E R I$ Relative excess risk of interaction

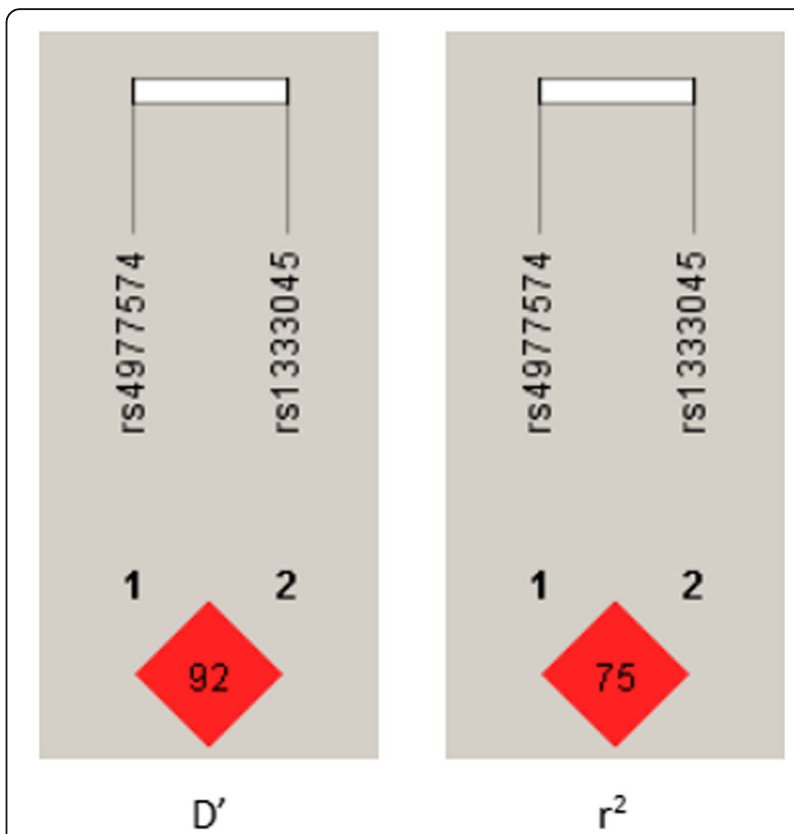

Fig. 2 Haplotype analysis between the two groups of rs4977574 and rs1333045

are monolayer continuous cells covering the inner surface of vessels with significant biological functions, including the regulation of thrombosis and coagulation, dilation of vascular smooth muscle, suppression of platelet adhesion and aggregation [30, 31]. The 9p21.3 risk allele in CHD is associated with altered expression of the CDKN2B-AS1 gene in blood. Evidence has demonstrated that CDKN2BAS1 is a new susceptibility gene for CHD [32-34]. Both rs4977574 and rs1333045 are ANRILs of the CDKN2BAS1 gene. Long noncoding RNAs have been shown to have a regulatory role in increasing cell proliferation and decreasing apoptosis in addition to participating in the inflammatory response.

In the present study, we recruited 855 inpatients, 598 cases with CHD confirmed by angiography as the CHD group and 257 subjects with normal coronary artery as the control group. In associating the two groups with SNPs, we analyzed their basic demographic information, including age, gender, smoking status, drinking status, and hypertension, and the following variable values, such as CKMB, TC, TG, HDL, LDL, ApoA, ApoB, Glu, Bun and Cre, which may be related to CHD.

The results of allelic and genotype logic regression showed that the $\mathrm{G}$ allele may be associated with a higher risk of CHD $(P=0.003, O R=1.371,95 \% C I=1.113-$ 1.689), and allele $\mathrm{T}$ was likely to reduce the occurrence of coronary events $(P=0.035, O R=0.798,95 \% C I=$ 0.649-0.982). The frequencies of genotypes GG $(P=$ 0.042, $O R=1.421,95 \% C I=1.014-1.993)$ and AG $(P=$ 
0.004, $O R=1.849,95 \% C I=1.217-2.810)$ were increased in the CHD group compared with the control group. In comparison to genotype $\mathrm{CC}$, genotype $\mathrm{TC}$ significantly reduced the incidence of $\mathrm{CHD}(P=0.035, O R=0.641$ and $95 \% C I=0.424-0.970)$. We also evaluated the association between the severity of coronary atherosclerosis and SNP polymorphisms. We found that the degree of vascular stenosis estimated by the Gensini score differed in relation to the rs4977574 genotype. We found that a significantly higher Gensini score appeared in the heterozygous AG genotype and the homozygous GG genotype compared with the AA genotype. This proves that allele $\mathrm{G}$ is positively correlated with the severity of $\mathrm{CHD}$. In addition, we analyzed the distribution of clinical parameters in different models. In the recessive model of rs4977574, the genotype AA+AG carriers had significantly higher levels of ApoA $(P=0.028)$ than the GG genotype. In the dominant model of rs1333045, the serum levels of LDL in the CC genotype were higher than in the TC + TT genotype $(P=0.032)$, and the serum levels of ApoA in the CC genotype were significantly lower than in the TC+TT genotype $(P=0.049)$. The conclusion that allele $\mathrm{A}$ and allele $\mathrm{T}$ are protective factors of CHD should be confirmed more powerfully. Therefore, we suspected that this phenomenon was related to genes affecting the development of $\mathrm{CHD}$ by regulating lipid metabolism. Furthermore, we conducted an analysis of CHD prevalence and gene-environment interactions with the occurrence of $\mathrm{CHD}$. It can be seen that genotype GG and AG are more susceptible to CHD than genotype AA when other variables are present. In comparison to genotype $\mathrm{CC}$, genotype $\mathrm{TC}$ significantly reduced the incidence of $\mathrm{CHD}$. When traditional risk factors and susceptibility genes coexist, the incidence of CHD is greatly increased.

Nevertheless, the other downside is that in haplotype analysis, it shows that there is no linkage disequilibrium between two sites, but the data showed a degree of association between the two sites that on the same gene. The deeper connection between the two sites needs to be explored further.

In the present study, due to the limited collection of clinical variables, further mechanisms exploring variables were not evaluated in the model building process. At the same time, the sample size of the case-control study was comparatively small, and the age and gender were not well matched. Moreover, the ratio of case and control was not 1:1 due to the consecutiveness of the recruited subjects and the invasiveness of coronary angiography. Therefore, we could not exclude a chance of random positive finding of the genotype association. Further studies utilizing a well-matched group with a larger sample size are warranted to increase the confidence of our findings. However, we can draw some conclusions from this study, and it also lays the foundation for further research in the future.

\section{Conclusions}

We identified that the SNPs tested in the case-control study were significantly associated with CHD. We proved that allele G of rs4977574 may be associated with a higher risk of CHD, and allele $\mathrm{T}$ of rs1333045 was likely to reduce the incidence of coronary events. When susceptibility factors (age $\geq 59.5$, male, smoking, hypertension, $\mathrm{CKMB} \geq 25.9$, Glu $\geq 5.445$, Cre $\geq 73.2$ ) and susceptibility genes (allele G or allele C) coexist, the incidence of CHD is greatly increased. However, further studies are needed to explain SNPs rs4977574 and rs1333045 in the specific pathogenesis of CHD.

\section{Supplementary information}

Supplementary information accompanies this paper at https://doi.org/10. 1186/s12881-020-0965-x

Additional file 1: Table S1. CHD incidence by interactions with environmental factors.

Additional file 2: Table S2. Serological biomarkers in the overdominant model.

\section{Abbreviations \\ ANIRL: Antisense noncoding RNA in the INK4 locus; ApoA: Apolipoprotein A; ApoB: Apolipoprotein B; AUC: Area under curve; Bun: Blood urea nitrogen; CHD: Coronary heart disease; $\mathrm{Cl}$ : Confidence intervals; \\ CKMB: Creatinephosphokinase isoenzyme; Cre: Creatinine; Glu: Glucose; GWAS: Genome-wide association studies; HDL-C: High-density lipoprotein cholesterol; HWE: Hardy-Weinberg equilibrium; LD: Linkage disequilibrium; LDL-C: Low-density lipoprotein cholesterol; LncRNA: Long noncoding RNA; OR: Odds ratio; PCR: Polymerase chain reaction; RERI: Relative excess risk of interaction; ROC: Receiver operating characteristic; SAP: Shrimp alkaline phosphatase; SE: Standard error; SNPS: Single nucleotide polymorphisms; TC: Total cholesterol; TG: Triglyceride}

\section{Acknowledgements}

This study received support from the National Natural Science Foundations of China (No. 81170180, 30400173 and 30971257) and the Priority Academic Program Development of Jiangsu Higher Education Institutions. Dr. En-Zhi Jia is an Assistant Fellow at the Collaborative Innovation Center for Cardiovascular Disease Translational Medicine.

\section{Authors' contributions}

As the guarantor, LH, JXY, and EZJ conceived the study. SH, CHZ and QWJ initially drafted the paper. JZ, FHA, ZHC and LHL collected and analysed the data. LSW, WZM and GXX revised the manuscript. We ensure that all authors have read and approved the content of the manuscript.

\section{Funding}

This study received support from the National Natural Science Foundations of China (No. 81170180, 30400173 and 30971257) and the Priority Academic Program Development of Jiangsu Higher Education Institutions.

\section{Availability of data and materials}

The datasets used or analysed during the current study are available from the corresponding author upon reasonable request.

Ethics approval and consent to participate

The study was performed in accordance with the protocol approved by the ethics committee of the First Affiliated Hospital of Nanjing Medical University 
and the Friendship Hospital of Ili Kazakh Autonomous Prefecture in China and all selected subjects signed informed consent.

\section{Consent for publication}

Not Applicable.

\section{Competing interests}

The authors declare that they have no competing interests.

\section{Author details}

${ }^{1}$ Department of Cardiovascular Medicine, The First Affiliated Hospital of Nanjing Medical University, Guangzhou Road 300, Nanjing, Jiangsu Province 210029, China. ${ }^{2}$ Department of Cardiovascular Medicine, The Friendship Hospital of Ili Kazakh Autonomous Prefecture, Yining, China. ${ }^{3}$ Department of Rehabilitation Medicine, The First Affiliated Hospital of Nanjing Medical University, Nanjing, China.

Received: 21 November 2018 Accepted: 27 January 2020

Published online: 17 February 2020

\section{References}

1. Owan TE, Roe MT, Messenger JC, Dai D, Michaels AD. Contemporary use of adjunctive thrombectomy during primary percutaneous coronary intervention for ST-elevation myocardial infarction in the United States. Catheter Cardiovasc Interv. 2012;80:1173-80.

2. Chien KL, Hsu HC, Su TC, Chang WT, Chen PC, Sung FC, et al. Constructing a point-based prediction model for the risk of coronary artery disease in a Chinese community: a report from a cohort study in Taiwan. Int J Cardiol. 2012;157:263-8.

3. Tada N, Maruyama C, Koba S, Tanaka H, Birou S, Teramoto T, et al. Japanese dietary lifestyle and cardiovascular disease. J Atheroscler Thromb. 2011;18: 723-34.

4. Kangas-Kontio T, Huotari A, Ruotsalainen $\mathrm{H}$, Herzig KH, Tamminen M, AlaKorpela $\mathrm{M}$, et al. Genetic and environmental determinants of total and highmolecular weight adiponectin in families with low HDL-cholesterol and early onset coronary heart disease. Atherosclerosis. 2010;210:479-85.

5. Feng $L$, Nian $S-Y$, Hao $Y-L, X u$ W-B, Ye D, Zhang $X-F$, et al. A single nucleotide polymorphism in the stromal cell-derived factor 1 gene is associated with coronary heart disease in Chinese patients. Int J Mol Sci. 2014;15:11054-63

6. Kanu JS, Gu Y, Zhi S, Yu M, Lu Y, Cong Y, et al. Single nucleotide polymorphism rs3774261 in the AdipoQ gene is associated with the risk of coronary heart disease (CHD) in Northeast Han Chinese population: a casecontrol study. Lipids Health Dis. 2016:15:6.

7. Cunnington MS, Koref MS, Mayosi BM, Burn J, Keavney B. Chromosome 9p21 SNPs associated with multiple disease phenotypes correlate with ANRIL expression. PLoS Genet. 2010;6:e1000899.

8. Yap KL, Li S, Munoz-Cabello AM, Raguz S, Zeng L, Mujtaba S, et al. Molecular interplay of the noncoding RNA ANRIL and methylated histone $\mathrm{H3}$ lysine 27 by polycomb CBX7 in transcriptional silencing of INK4a. Mol Cell. 2010;38:662-74.

9. Kotake Y, Nakagawa T, Kitagawa K, Suzuki S, Liu N, Kitagawa M, et al. Long non-coding RNA ANRIL is required for the PRC2 recruitment to and silencing of p15(INK4B) tumor suppressor gene. Oncogene. 2011;30:1956-62.

10. McPherson R, Pertsemlidis A, Kavaslar N, Stewart A, Roberts R, Cox DR, et al. A common allele on chromosome 9 associated with coronary heart disease. Science. 2007;316:1488-91.

11. Scott LJ, Mohlke KL, Bonnycastle LL, Willer CJ, Li Y, Duren WL, et al. A genome-wide association study of type 2 diabetes in Finns detects multiple susceptibility variants. Science. 2007:316:1341-5.

12. Psaty BM, O'Donnell CJ, Gudnason V, Lunetta KL, Folsom AR, Rotter Jl, et al. Cohorts for heart and aging research in genomic epidemiology (CHARGE) consortium: design of prospective meta-analyses of genome-wide association studies from 5 cohorts. Circ Cardiovasc Genet. 2009:2:73-80.

13. Jarinova $O$, Stewart AF, Roberts $R$, Wells G, Lau P, Naing T, et al. Functional analysis of the chromosome 9p21.3 coronary artery disease risk locus. Arterioscler Thromb Vasc Biol. 2009:29:1671-7.

14. Liu Y, Sanoff HK, Cho H, Burd CE, Torrice C, Mohlke KL, et al. INK4/ARF transcript expression is associated with chromosome 9p21 variants linked to atherosclerosis. PLoS One. 2009;4:e5027.

15. Broadbent HM, Peden JF, Lorkowski S, Goel A, Ongen H, Green F, et al. Susceptibility to coronary artery disease and diabetes is encoded by distinct, tightly linked SNPs in the ANRIL locus on chromosome 9p. Hum Mol Genet. 2008;17:806-14.

16. Liu Y, Sanoff HK, Cho H, Burd CE, Torrice C, Ibrahim JG, et al. Expression of p16(INK4a) in peripheral blood T-cells is a biomarker of human aging. Aging Cell. 2009;8:439-48.

17. Sakalar C, Gurbuz E, Kalay N, Kaya MG. Higher frequency of rs4977574 (the G Allele) on chromosome 9p21.3 in patients with myocardial infarction as revealed by PCR-RFLP analysis. Tohoku J Exp Med. 2013;230:171-6.

18. Judkins MP. A percutaneous transfemoral technique. Radiology. 1967;89:819-21.

19. Sun X, Zhang M, Sanagawa A, Mori C, Ito S, Iwaki S, et al. Circulating microRNA-126 in patients with coronary artery disease: correlation with LDL cholesterol. Thromb J. 2012;10:16

20. Lawler PR, Filion KB, Dourian T, Atallah R, Garfinkle M, Eisenberg MJ. Anemia and mortality in acute coronary syndromes: a systematic review and metaanalysis. Am Heart J. 2013;165:143-53.e5.

21. O'Connor NT, Cederholm-Williams S, Copper S, Cotter L. Hypercoagulability and coronary artery disease. Br Heart J. 1984;52:614-6.

22. Kannel WB, McGee DL. Diabetes and glucose tolerance as risk factors for cardiovascular disease: the Framingham study. Diabetes Care. 1979;2:120-6.

23. Hulley SB, Rosenman RH, Bawol RD, Brand RJ. Epidemiology as a guide to clinical decisions. The association between triglyceride and coronary heart disease. N Engl J Med. 1980;302:1383-9.

24. May AL, Kuklina EV, Yoon PW. Prevalence of cardiovascular disease risk factors among US adolescents, 1999-2008. Pediatrics. 2012;129:1035-41.

25. Boekholdt SM, Arsenault BJ, Mora S, Pedersen TR, LaRosa JC, Nestel PJ, et al. Association of LDL cholesterol, non-HDL cholesterol, and apolipoprotein B levels with risk of cardiovascular events among patients treated with statins: a meta-analysis. Jama. 2012;307:1302-9.

26. Tsimikas S, Hall JL. Lipoprotein(a) as a potential causal genetic risk factor of cardiovascular disease: a rationale for increased efforts to understand its pathophysiology and develop targeted therapies. J Am Coll Cardiol. 2012; 60:716-21.

27. Gensini GG. A more meaningful scoring system for determining the severity of coronary heart disease. Am J Cardiol. 1983;51:606.

28. Zou JG, Ma YT, Xie X, Yang YN, Pan S, Adi D, et al. The association between CYP1A1 genetic polymorphisms and coronary artery disease in the Uygur and Han of China. Lipids Health Dis. 2014:13:145.

29. Madjid M, Willerson JT. Inflammatory markers in coronary heart disease. $\mathrm{Br}$ Med Bull. 2011;100:23-38.

30. Tasaki H. Low-density lipoprotein apheresis in the prevention of recurrent coronary heart disease: a review. Ther Apher Dial. 2003;7:408-12.

31. Campo G, Pavasini R, Pollina A, Tebaldi M, Ferrari R. Coagulation factors and recurrence of ischemic and bleeding adverse events in patients with acute coronary syndromes. Thromb Res. 2013:132:151-7.

32. Holdt LM, Beutner F, Scholz M, Gielen S, Gabel G, Bergert H, et al. ANRIL expression is associated with atherosclerosis risk at chromosome 9p21. Arterioscler Thromb Vasc Biol. 2010;30:620-7.

33. Peden JF, Hopewell JC. A genome-wide association study in Europeans and[ ]outh Asians identifies five new loci for coronary artery disease. Nat Genet. 2011:43:339-44.

34. Harismendy O, Notani D, Song X, Rahim NG, Tanasa B, Heintzman N, et al. 9p21 DNA variants associated with coronary artery disease impair interferon-gamma signalling response. Nature. 2011;470:264-8.

\section{Publisher's Note}

Springer Nature remains neutral with regard to jurisdictional claims in published maps and institutional affiliations.

Ready to submit your research? Choose BMC and benefit from:

- fast, convenient online submission

- thorough peer review by experienced researchers in your field

- rapid publication on acceptance

- support for research data, including large and complex data types

- gold Open Access which fosters wider collaboration and increased citations

- maximum visibility for your research: over $100 \mathrm{M}$ website views per year

At BMC, research is always in progress.

Learn more biomedcentral.com/submissions 